\title{
4 Die Herausbildung mentaler Grundeinstellungen in Frankreich und in Deutschland und die Wahrnehmung des jeweils Anderen in der deutsch-französischen Begegnung
}

\subsection{Einleitung}

Die vorangegangenen Ausführungen zum Unterschied von ,Zivilisation“ und ,Kultur' lassen sich in einer interkulturellen Perspektive bezogen auf die Formen der Kommunikation erheblich präzisieren, wenn man die Wahrnehmung des jeweils Anderen näher in den Blick nimmt. Dabei ist die Besinnung auf die jeweilige Sprache zentral. Frankreich findet sein nationales Selbstverständnis vor allem in seiner ,grandeur‘. Dieses Gefühl der ,grandeur' resultiert zu einem wesentlichen Teil aus der kulturellen Ausnahmestellung, die das Land spätestens seit dem 17. Jahrhundert, dem ,grand siècle‘, innehat und die es seinem nationalen Selbstverständnis entsprechend sich selbst über lange Zeit als ,exception culturelle de la France' attestiert. Dieses Selbstbild ist weitgehend identisch mit dem Fremdbild, welches sich die anderen europäischen Nationen über lange historische Phasen von Frankreich machen. In seinem Briefroman Lettres persanes (1721) zu Beginn der Frühaufklärung lässt Montesquieu zwei Perser wie selbstverständlich nach Frankreich reisen. In einem der einleitenden Briefe erklärt der Protagonist Usbeck seinem Freund Rustan, er habe den Intrigen der persischen Hofgesellschaft entfliehen wollen, weil er der Wahrheit und Wissenschaft verpflichtet sei ${ }^{1}$. Allein deshalb scheint es für Montesquieu selbstverständlich zu sein, dass die Perser Frankreich als Reiseziel anvisieren. Angesichts der zivilisatorischen Überlegenheit seines Landes bekundet der fiktive Herausgeber der Briefe in der Einleitung des Romans nicht ohne eine gewisse Überheblichkeit seinen Respekt gegenüber den detaillierten Kenntnissen der Perser. Dies begründet er damit, dass die Franzosen und ihre Zivilisation für jedermann offen und transparent seien. Die Bemerkung ist vor allem wegen ihrer Spitze gegen Frankreichreisende aus Deutschland interessant, die man zu dieser Zeit (und nicht nur zu dieser Zeit) keineswegs als Abgesandte einer Kulturnation wahrnimmt. Subtile

1 Montesquieu, Lettres persanes, hrsg. von Paul Vernière (Classiques Garnier), Paris, Garnier, 1975, S. $21 \mathrm{f}$.

Ә Open Access. (c) 2021 Michael Bernsen, publiziert von De Gruyter (c))BY-NC-ND Dieses Werk ist lizenziert unter der Creative Commons Attribution 4.0 Lizenz.

https://doi.org/10.1515/9783110758009-004 
Beobachtungen und Detailkenntnisse der französischen Zivilisation wie die der Perser traut der Herausgeber der Lettres persanes deutschen Reisenden nicht zu:

Il y a une chose qui m'a souvent étonné: c'est de voir ces Persans quelquefois aussi instruits que moi-même des mœurs et des manières de la Nation, jusqu'à en connaître les plus fines circonstances, et à remarquer des choses qui, j'en suis sûr, ont échappéà bien des Allemands qui ont voyagé en France. J'attribue cela au long séjour qu'ils y ont fait; sans compter qu'il est plus facile à un asiatique de s'instruire des mœurs des Français dans un an, qu'il ne l'est à un Français de s'instruire des mœurs des Asiatiques dans quatre, parce que les uns se livrent autant que les autres se communiquent peu. ${ }^{2}$

Diese französische Selbsteinschätzung der eigenen Zivilisation als überlegen und zugleich weltoffen, so dass sie die Asiaten selbstverständlich kennen, wird nicht nur während des ,siècle classique‘ und der im 18. Jahrhundert folgenden Aufklärung sondern auch noch ein Jahrhundert später aus deutscher Sicht geteilt, wenn z. B. Friedrich Nietzsche immer wieder die herausragende Stellung Frankreichs unterstreicht und sich sogar zu der Behauptung versteigt, er lese Schopenhauer lieber auf Französisch als auf Deutsch, weil dieser mehr im französischen Geist als im deutschen beheimatet sei ${ }^{3}$. Für Nietzsche bleibt Frankreich der Fluchtpunkt der - wie er sagt - ,Kultur` in Europa:

Auch jetzt noch ist Frankreich der Sitz der geistigsten und raffiniertesten Cultur Europa's und die hohe Schule des Geschmacks $[\ldots]^{4}$

Alles, was Europa an Kultur hervorgebracht habe, gehe im Wesentlichen auf die Leistung Frankreichs zurück:

[...] die europäische noblesse - des Gefühls, des Geschmacks, der Sitte, kurz, das Wort in jedem hohen Sinne genommen - ist Frankreich's Werk und Erfindung [... $]^{5}$

Insbesondere wehrt sich Nietzsche gegen das deutsche Vorurteil, Frankreichs zivilisatorische Errungenschaften seien rein äußerlich und oberflächlich:

2 S. 8.

3 „In diesem Frankreich des Geistes, welches auch das Frankreich des Pessimismus ist, ist heute schon Schopenhauer mehr zu Hause als er es je in Deutschland war; sein Hauptwerk zwei Mal bereits übersetzt, das zweite Mal ausgezeichnet, so dass ich es jetzt vorziehe, Schopenhauer französisch zu lesen [...]“ (Nietzsche contra Wagner. Aktenstücke eines Psychologen, Leipzig, Naumann, 1889; online: http://www.nietzschesource.org/\#eKGWB/NW-Wohin) (,Wohin Wagner gehört").

4 Jenseits von Gut und Böse. Vorspiel einer Philosophie der Zukunft, Leipzig, Naumann, 1886, Nr. 254; online: http://www.nietzschesource.org/\#eKGWB/JGB-254.

5 Jenseits von Gut und Böse Nr. 253; online: http://www.nietzschesource.org/\#eKGWB/JGB-254. 
Ferne davon, oberflächlich zu sein, hat ein grosser Franzose immer doch seine Oberfläche, eine natürliche Haut für seinen Inhalt und seine Tiefe $[\ldots]^{6}$

Die lang hergebrachte Selbst- und Fremdwahrnehmung Frankreichs spielt bis in die Gegenwart ihre Rolle, in der allerdings zunehmend über den Verlust der französischen kulturellen Vorrangstellung in der Welt geklagt bzw. dieser beschrieben wird. Ihr steht die ganz andere Wahrnehmung Deutschlands und der Deutschen in Frankreich gegenüber.

Als 2013 im Pariser Louvre eine gemeinsame deutsch-französische Ausstellung deutscher Kunst unter dem Titel De l'Allemagne 1800-1939. De Friedrich à Beckmann eröffnet wird, kommt es im Nachhinein zu einem heftigen Streit über das Konzept der Ausstellung und ihre Ankündigung. Man hatte, ohne die deutschen Kuratoren in die letztendliche Konzeptionalisierung der Ausstellung einzubinden, die ausgestellten Werke unter die auf Nietzsche zurückgehenden Kategorien ,Apollinisch“ und ,Dionysisch' subsumiert. In der Ankündigung der Ausstellung, die überdies ein Musterbeispiel der Kunst des Impliziten in der wissenschaftlichen Diskussion darstellt, hatte es geheißen:

La notion de Kultur, concept hérité de la philosophie des Lumières, est apparue comme la plus susceptible de constituer le terreau sur lequel inventer une tradition allemande moderne. Si l'occupation napoléonienne a pu favoriser la prise de conscience de cette unité, fournissant l'arrière-plan politique aux premières expérimentations romantiques, la montée du nazisme, à l'autre bout du parcours chronologique, a mis en évidence la dimension tragique de ce concept, sans pour autant réussir à l'anéantir. ${ }^{7}$

Diese Ankündigung wurde auf deutscher Seite als Affront angesehen. Sie zeigt, wie lang überlieferte, quasi mythische Sichtweisen auf den anderen, bis in die Gegenwart virulent bleiben und - was zu besonderen Irritationen führte - unterschwellig in den Ankündigungstext der Ausstellung eingebracht wurden. Die Ankündigung offenbart, dass dem Ausstellungskonzept des ,Apollinischen“ und ,Dionysischen' Deutschlands die in Frankreich tradierte Vorstellung von den ,Deux Allemagnes‘ zugrunde liegt, wie sie in den vierziger Jahren des 19. Jahrhunderts, also kurz nach dem Beginn der eigentlichen Wahrnehmung Deutschlands in Frankreich während der Romantik, aufgekommen war: Auf der einen Seite ist die Rede von jenem Deutschland der Dichter und Denker der Romantik sowie des Idealismus, auf der anderen Seite vom militaristischen Deutschland,

6 Morgenröthe. Gedanken über die moralischen Vorurtheile, Leipzig, Fritzsch, 1887, Nr. 192; online: http://www.nietzschesource.org/\#eKGWB/M-192.

7 Online: http://www.louvre.fr/expositions/de-l-allemagne-1800-1939-de-friedrich-beckmann. 
das im deutsch-französischen Krieg 1870-1871 Elsass-Lothringen eingenommen hatte und im 20. Jahrhundert maßgeblicher Auslöser zweier Weltkriege sowie der Nazidiktatur war. Eine zusätzliche Provokation über diese mythisch verkürzte Sicht hinaus liegt darin, dass selbst dem Deutschland der herausragenden Kultur während der Romantik die Eigenständigkeit seiner Entstehung durch den Verweis auf die französische Aufklärung sowie Napoleon abgesprochen wird: Zwar heißt es in der Ausstellungsankündigung, die Nazizeit habe das romantische Kulturerbe Deutschlands nicht zerstören können. Gleichzeitig wird jedoch erklärt, dass das in Deutschland am Ende des 18. Jahrhunderts entstehende nationale Kulturbewusstsein vor allem auf die Besetzung des Landes durch Napoleon zurückzuführen sei. Diese Aussage ist indirekt und gleichzeitig bewusst ambivalent: Sie hat auf der einen Seite eine gewisse Berechtigung, da die Opposition gegen Napoleon das deutsche Nationalbewusstsein und damit einen Teil der Besinnung auf die deutsche Kultur wesentlich geprägt hat. Auf der anderen Seite wird dieser Besinnung damit zugleich ihre Eigenständigkeit abgesprochen, da sie ja ohne die Napoleonische Besetzung nicht zustande gekommen wäre. Überdies wird unterstellt, dass dem deutschen Konzept der ,Kultur‘ eine tragische Dimension innewohnt. Will man die interkulturellen Spezifika der deutsch-französischen Begegnung verstehen und die Details spezifischer Verhaltensweisen in den Blick nehmen, so ist eine Betrachtung der historischen Entwicklung solcher Sichtweisen auf den jeweils Andern erhellend.

\subsection{Frankreichs, exception culturelle‘: die französische Eigenwahrnehmung und die deutsche Perspektive auf das Land}

Zur besonderen Stellung der französischen Kultur findet sich schon zur Zeit der Renaissance in den Épithètes (1571) des französischen Humanisten Maurice de la Porte ein bemerkenswerter Eintrag. La Portes alphabetisch geordnetes Lexikon, welches mit 3777 Gattungs- und Eigennamen ,natürliche‘ Eigenschaften der genannten Bezeichnungen erfassen will (,épithètes de nature‘), verzeichnet unter dem Eintrag „Franzosen“ („François“):

Humains, charitables, vaillans ou valeureux, guerriers, forts, magnanimes, ingénieux parisiens, accostables, fideles, amateurs des lettres, prompts, curieux, doctes, volontaires, doux, libéraux, généreux, débonnaires, chevalereux.

Ce peuple [...] est tres affectionné à la religion \& piété catholique, et s’adonne volontiers à l'estude des sciences, et arts libéraus, étant très désireux de la connaissance des langues, facilement il compatit avec les personnes de quelque pays qu'elles soient, et surpasse toute autre nation en courtoisie et humanité: Davantage il est fort belliqueux, usant plus de cœur 
et hardiesse, que d'art en combattant, et est aussi prompt et inventif, mais il ne se hâte qu'en nécessité. ${ }^{8}$

Die Franzosen werden als tapfere Krieger beschrieben, die sich, so heißt es wenig später im Artikel, vor allem gegen die Unterwerfung fremder Mächte zur Wehr setzen. Überwiegend werden die Franzosen jedoch als rational bestimmtes und kulturell vorbildliches Volk gezeigt. Selbst dort, so am Ende des Eintrags, wo die französischen Krieger eher mit Herz und Kühnheit als mit Verstand und Kriegskunst kämpfen, sind sie überlegt, d.h. sie handeln erfindungsreich und nicht überstürzt. Ansonsten erfolgen Zuschreibungen kultureller Art: Aristokratische Persönlichkeitsideale wie die ,magnanimité‘, die ,liberalité‘, die ,fidélité‘ und ein chevalereskes Verhalten sind gepaart mit Gelehrsamkeit und Interesse an der Literatur. Die Franzosen werden, das zeigt dann vor allem der Eintrag zu „Frankreich“ („France“), kurzerhand mit den Parisern identifiziert:

Perle du monde, indomptable, fertile, belliqueuse, florissante, riche, salubre, docte, célèbre, féconde, généreuse, invincible, peuplée ou populeuse, école de vertu.

Ce mot généralement pris signifie tout ce que le Roi de France domine, mais ce qui est en particulier nommé le pays de France, comprend seulement ce qu'on appelle l'île de France, et le pays de Goelle. Or combien que cela soit de petite étendue, néanmoins il enclot cette grande et fameuse ville de Paris, dont l'excellence est telle que elle ennoblit le reste de la France, laquelle tant pour la température de l'air, fertilité de la terre, abondance de tous genres de fruits, et autres innumérables commodités, que le Ciel plus prodigalement que libéralement lui a élargies, qu'aussi pour la piété, religion, intégrité de mœurs, profession des bonnes lettres, justice équitable, magnanimité de courages et plusieurs vertus rares et antiques (qui est la vraie et solide louange) a toujours obtenu sans controverse le premier lieu entre toutes les régions de l'Europe, et en est appelée Mère des arts, des armes, et des lois, et douce nourrice des hommes. ${ }^{9}$

Die lange Ausführung der Tugenden des Landes Frankreich zielt auf die Definition Frankreichs als kulturell überlegener Nation. Das Land erscheint als ,kopfgesteuert', da die gesamte Charakterisierung auf Paris gemünzt ist, welches von oben herab dem Land seine Prägung gibt. Aus La Portes Ausführungen lassen sich bereits jene Vorstellungen von der Ausnahmestellung der französischen Kultur ableiten, die während des Absolutismus und der Klassik unter Louis XIV europäische Dimensionen gewinnt. 1635 gründet der Kardinal Richelieu im Auftrag des Königs Louis XIII die Académie Française. In der Gründungsurkunde, den Lettres patentes pour l'établissement de l'Académie Françoise, heißt es, das Ziel der Akade-

8 Maurice de la Porte, Les Épithètes, Paris, Gabriel Buon, 1571; zitiert nach der sprachlich modernisierten Version online: http://www.preambule.net/epithetes/f/francais.html.

9 Online: http://www.preambule.net/epithetes/f/france.html. 
mie sei die Festsetzung fixer Regeln der französischen Sprache (,établir des règles certaines“), um das Französische als Sprache aller Künste und Wissenschaften zu etablieren: „pour rendre le langage françois non seulement élégant, mais capable de traiter tous les arts et toutes les sciences [... ]"10 Lässt sich hier bereits die Vorstellung von der Universalität bezogen auf die französische Sprache und Kultur erkennen, so wird diese Vorstellung im 17. Jahrhundert auf die gesamte Kultur Frankreichs ausgedehnt. Richelieu und sein Nachfolger Mazarin etablieren ein staatliches Mäzenatentum und fördern auf diese Weise die Wissenschaften, die Künste sowie die Literatur, welche sich als Propagandainstrument für den aufkommenden absolutistischen Staat in Dienst nehmen lassen. Dies gilt insbesondere für den ersten Kanzler der Akademie und Günstling Richelieus, Jean Desmarets de Saint-Sorlin, der als einer der Wegbereiter der Querelle des anciens et des modernes die moderne Position der Überlegenheit der zeitgenössischen französischen Kultur über die der Antike vertritt. In seinem monumentalen Epos Clovis ou la France chrétienne (1657) begründet er die christlichen Ursprünge der französischen Monarchie, die alle anderen Monarchien Europas überrage:

Quittons les vains concerts du profane Parnasse.

Tout est auguste \& saint au sujet que j'embrasse.

A la gloire des Lis je consacre ces vers.

L'entonne la trompette; \& respans dans les airs

Les faits de ce grand roy, qui sous l'eau du baptesme

Le premier de nos rois courba son diadême;

Qui sage \& valeureux, de ses fatales mains

Porta le coup mortel aux restes des Romains;

Mit la Saone \& le Rhin sous sa vaste puissance;

Fit tomber sous son bras la Gothique vaillance;

Et faisant aux vaincus aimer ses justes loix,

Donna le nom de France à l'empire Gaulois. ${ }^{11}$

Das französische Königtum hat demzufolge nicht nur die Kultur der heidnischen Antike hinter sich gelassen (,profane Parnasse“). Clovis repräsentiert bereits den Ruhm und die Größe (,ce grand roy“), die Desmarets den absolutistischen bourbonischen Herrschern seiner eigenen Zeit beimisst, wobei er den fränkischen König Chlodwig aus der Dynastie der Merowinger kurzerhand zum Bourbonen macht („la gloire des Lis“). Gemäß der Anschauung von der translatio imperii tritt das französische Königtum an die Stelle des Römischen Reichs („Porta le

10 Abgedruckt auf der Internetseite der Académie: „Statuts et règlements”, S. 7-11; online: http: //www.academie-francaise.fr/sites/academie-francaise.fr/files/statuts_af_0.pdf.

11 Clovis ov la France chrestienne. Poeme heroiqve, Paris, Avgvstin Courbe, Henry Gras et Iaqves Roger, 1657, Chant 1, V. 1-12. Hervorhebungen von Vf. 
coup mortel aux restes des Romains [...]“), was ihm von vorneherein einen universalistischen Anspruch verleiht. Seine Grenzen, so heißt es, erstreckten sich nicht nur bis zum Rhein, wodurch die in Frankreich dann vor allem im 19. Jahrhundert immer wieder bemühte, schon bei den Römern geläufige Vorstellung von der natürlichen Grenze zu Deutschland fundiert wird. Desmarets geht sogar noch weiter: Clovis habe nicht nur die letzten gallisch-römischen Heerführer besiegt (,Porta le coup mortel aux restes des Romains [...]“). Er habe auch - was durchaus geschichtskonform ist - die weiteren fränkischen Heerführer sowie die Westgoten auf dem Territorium des späteren Frankreich unter seine Kontrolle gebracht. Im Epos lässt Desmarets Clovis nun aber auch noch die restlichen germanischen Stämme besiegen, was den fränkischen König quasi zum europäischen Herrscher par excellence macht. Desmarets nimmt damit nicht nur die historische Entwicklung unter dem auf territoriale Expansion bedachten König Louis XIV vorweg. Indem er - in einer einzigartigen Geschichtsklitterung - Clovis auch Arminius, den Führer der Cherusker und erfolgreichen Widersacher Roms besiegen lässt, wird der Anspruch Frankreichs auf die Führung in Europa überdeutlich. Die Germanen werden auf diese Weise ihrer Führungsfigur beraubt, die seit dem 16. Jahrhundert, der Wiederentdeckung der Germania des Tacitus, allmählich zum mythischen Nationalhelden der Deutschen aufsteigt.

\author{
De cherusques archers une troupe infinie \\ Marche avec cent drapeaux sous le noble Arminie, \\ Issu de ce grand chef dont l'indomptable cœur \\ Des superbes Romains fut mille fois vainqueur, \\ Qui d'un sort obstiné, fatal à tant d'armées, \\ Dans ses pièges surprit cent têtes renommées. \\ Tous ces peuples sont fiers, nourris aux régions \\ Où le soc traîne encor les os des légions, \\ Près des bords du Weser et de la forêt sombre \\ Où souvent de Varus on voit paraître l'ombre \\ Grande, pâle et jetant de gémissantes voix, \\ Des siens cherchant encor les restes dans les bois. ${ }^{12}$
}

Als Charles Perrault dann am 27. Januar 1687 in der Académie sein berühmtes Gedicht Le Siècle de Louis le Grand vorträgt, wird der Universalismusanspruch der französischen Kultur endgültig zementiert. Das Zeitalter Ludwigs könne problemlos mit dem des Augustus mithalten: „[...] l'on peut comparer sans craindre d'estre injuste / Le Siecle de LOUIS au beau Siecle d'Auguste."13 Ludwig und die Kultur des Versailler Hofs umgebe ein „unsterblicher Ruhm“ („une gloire immor-

12 Chant 19, V. 7473-7484.

13 Le Siecle de Louis le Grand. Poeme, Paris, Jean Baptiste Coignard, 1687, S. 3. 
telle“). Von allen europäischen Königen sei er das perfekte Modell („LOUIS des grands Roys le parfait modele“14). Das Gedicht schließt mit der rhetorischen Frage: „Ciel, à qui nous devons cette splendeur immense, / Dont on voit eclatter nostre Siecle \& la France [...] "15 Diese Selbstdarstellung des ,grand siècle“ wirkt bis in die Gegenwart nach, was man z. B. nicht allein am Titel des Dictionnaire $d u$ Grand Siècle von François Bluche aus dem Jahr 1990 ablesen kann, sondern auch am Artikel „France“, der mit dem Zusatz „Rayonnement de la“ versehen ist und mit dem Satz beginnt: „La France, au XVIIe siècle, paraît aux étrangers, si rayonnante, qu'il leur arrive, comme le fait Grotius en 1628, de la comparer au royaume de Dieu."16

Auf indirekte Weise, mit einer Fremdeinschätzung des niederländischen Philosophen und Rechtsgelehrten Hugo Grotius, wird hier die Selbsteinschätzung der französischen Kultur des ,siècle classique‘ ins Feld geführt. Diese Sicht wird allerdings in den meisten europäischen Ländern weitgehend geteilt, so auch in Deutschland. Nicht nur dem aristokratischen Milieu, das den französischen Adel und die Hofgesellschaft in Versailles bewundernd nachahmt, sondern auch bürgerlichen Kreisen wird Frankreich in Deutschland lange Zeit zum Vorbild. 1687 kündigt der Jurist und Philosoph Christian Thomasius an der Universität Leipzig eine der ersten nicht-lateinischen Vorlesungen in deutscher Sprache an mit dem Titel: Christian Thomas eröffnet der Studirenden Jugend zu Leipzig in einem Discours Welcher Gestalt man denen Frantzosen in gemeinem Leben und Wandel nachahmen solle? ein Collegium über des Gratians Grund-Reguln/Vernünfftig/ klug und artig zu leben. Thomasius stellt fest, dass die Vorfahren der Deutschen, würden sie in die Gegenwart versetzt, „Teutschland [...] mit teutschen Frantz-Männern besetzt finden würden“17. Dies hält er allerdings keineswegs für verwerflich, sondern vertritt die pragmatische Position, dass man sich Nachahmenswertes aus Frankreich aneignen müsse, wovon er allerdings „närrische[r] Affectation“ und „Laster“ ausnimmt ${ }^{18}$ :

Derowegen sey es so, man ahme denen Franzosen nach, denn sie sind doch heut zu tage die geschicktesten Leute, und wissen allen Sachen ein recht Leben zugeben. ${ }^{19}$

14 S. 14.

15 S. 26.

16 Louis Trenard, „France (Rayonnement de la)”, in: F. B. (Hrsg.), Dictionnaire du Grand Siècle, Paris, Fayard, 1990, S. 615.

17 Abgedruckt in: Deutsche Literaturdenkmale des 18. und 19. Jahrhunderts, hrsg. von Bernhard Seuffert und August Sauer, Stuttgart, Göschen'sche Verlagshandlung, 1894, Bd. 51, N. F. 1, S. 1-36, hier: S. 3.

18 S. 5.

19 S. 7. 
Da die französische Sprache in Deutschland allenthalben verbreitet sei (,welche letztere fast bey uns naturalisiret worden“20), hält Thomasius es auch nicht für angebracht, die deutsche Sprache als Sprache der Gelehrsamkeit etablieren zu wollen:

Sollen wir uns bemühen die teutsche Sprache durchgehends in Hochachtung zubringen, um dadurch der Ausbreitung der Gelehrsamkeit den Weg zu bahnen? Diese dürfte schwerlich angehen, und würden wir wenig ausrichten, weil bißher schon eine geraume Zeit so viel kluge Köpffe, so viele edle Mitglieder der Fruchtbringenden Gesellschafft vergebens daran gearbeitet haben. ${ }^{21}$

Er folgt den Ausführungen des Jesuiten Dominique Bouhours trotz dessen herablassend verächtlichen Tonfalls, welcher in seinen sprachpuristischen Entretiens d'Ariste et d'Eugène bereits 1671 die herausragende kulturelle Stellung Frankreichs betont und angeblich gesagt hatte:

[...] daß alle Weißheit und aller Verstand von der Welt einzig und allein bey denen Franzosen anzutreffen sey, und daß alle anderen Nationes gegen die Franzosen gerechnet den Kopff mit Gritze gefüllet hätten.22

Im 18. Jahrhundert zieht diese herausragende Stellung der französischen Kultur in Europa erheblich größere Kreise. In der Zeit der Aufklärung, frz. ,Siècle des Lumières', verlagert sich die Kultur Frankreichs von Versailles in die Stadt, vom Hof in die Salons in Paris. Die Vorstellung von den ,lumières‘ richtet sich dabei nicht nur auf die Verbreitung des Wissens unter größeren Bevölkerungsschichten innerhalb Frankreichs, welche vor allem durch die beeindruckendste kulturelle Leistung des europäischen 18. Jahrhunderts bewerkstelligt wird, die monumentale Encyclopédie raisonnée. 1782 wird in der ,Classe des Belles-Lettres' der Preußischen Akademie die Preisfrage ausgeschrieben. „Qu'est-ce qui a fait de la langue Française la langue universelle de l'Europe? En quoi mérite-t-elle cette prérogative? Peut-on présumer qu'elle la conserve ?" Die Preisfrage hat die berühmte Antwort des einen der beiden Preisträgers hervorgebracht: Antoine Rivarols Discours sur l'universalité de la langue française. Rivarol geht davon aus, dass Europa durch eine kulturelle Einheit geformt ist, die sich einer einheitlichen Sprache bedient, des Französischen. Frankreich ist an die Stelle Roms getreten:

20 S. 19.

21 S. 19.

22 S. 26 f. Zu Thomasius vgl. Henning Scheffers, Höfische Konvention und die Aufklärung. Wandlungen des honnête-homme-Ideals im 17. und 18. Jahrhundert (Studien zur Germanistik, Anglistik und Komparatistik. 93), Bonn, Bouvier, 1980, S. 105-111. 
Le temps semble être venu de dire le monde français, comme autrefois le monde romain, et la philosophie, lasse de voir les hommes toujours divisés par les intérêts divers de la politique, se réjouit maintenant de les voir, d'un bout de la terre à l'autre, se former en république sous la domination d'une même langue. ${ }^{23}$

Für die „universalité de la langue française“ macht Rivarol die Dominanz der französischen Kultur ${ }^{24}$ in Europa verantwortlich. Das, was in Deutschland in der zweiten Hälfte des 18. Jahrhunderts zunehmend als Oberflächlichkeit der französischen Zivilisation angesehen wird, macht sich Rivarol für seine Argumentation zu Nutze: Die Mobilität der Franzosen, gemeint ist die spätestens am Versailler Hof verbreitete fortwährende Sucht der Aristokratie nach neuen Formen des ,divertissement‘, halte die Neugier der Europäer auf die kulturellen Entwicklungen Frankreichs aufrecht:

[...] la France a la politesse et la grâce; et non seulement elle a la grâce et la politesse, mais c'est elle qui fournit les modèles dans les mœurs, dans les manières et dans les parures. Sa mobilité ne donne pas à l'Europe le temps de se lasser d'elle. ${ }^{25}$

Nicht zuletzt bedingt durch den Einfluss der rationalistischen Philosophie Descartes sieht Rivarol die Überlegenheit der französischen Sprache als Ausdrucksform dieser Kultur vor allem in der Klarheit der Syntax begründet, die der Natur entspreche, was er im berühmten Diktum des Traktats zusammenfasst: „Ce qui n’est pas clair, n'est pas français.“26

Rivarols Schrift wurde vor allem deshalb preisgekrönt, weil sie auf einer Linie mit den Auffassungen des preußischen Königs Friedrichs II. lag, der kurz zuvor im Jahr 1780 seine Schrift De la littérature allemande; des défauts qu'on peut lui reprocher, quelles en sont les causes; et par quels moyens on peut les corriger veröffentlicht hatte. Der seit seiner Kindheit mehr in der französischen als in der deutschen Kultur und Sprache bewanderte preußische Herrscher stellt die Bedeutung der deutschen Kultur mangels nicht vorhandener Zeugnisse aufgrund kultureller Verspätung in Abrede. Die deutsche Sprache ist für Friedrich in keinem vorzeigbaren Zustand:

Je trouve une langue à demi-barbare, qui se divise en autant de dialectes différents que l'Allemagne contient de Provinces. ${ }^{27}$

23 Discours sur l'universalité de la langue française; online: http://www.pourlhistoire.com/ docu/discours.pdf, S. 2.

24 Und nicht wie bei den Römern das Militär (vgl. S. 14).

25 S. 10.

26 S. 17.

27 In: Deutsche Literaturdenkmale des 18. und 19. Jahrhunderts, Bd. 16, S. 4. 
Um diesen Missstand abzustellen, empfiehlt der Herrscher ganz im Sinne der späteren Schrift Rivarols an der Klarheit des Deutschen zu arbeiten und sich damit logischerweise an französischen Vorbildern zu orientieren:

Examinons donc ce qu'il reste à faire pour arracher de nos champs toutes les ronces de la barbarie qui s’y trouvent encore, et pour accélérer ces progrès si désirables auxquels nos compatriotes aspirent. [...] il faut commencer par perfectionner la Langue; [...] elle a besoin d'être maniée par des mains habiles. La clarté est la premiére regle que doivent se prescrire ceux qui parlent et qui écrivent $[\ldots]^{28}$

Friedrich endet mit der Feststellung, dass das Französische der ,europäische passe-partout' sei und er schließt für Deutschland die Hoffnung an, dass die zu spät Gekommenen manchmal ihre Vorbilder überholen:

Sous le règne de Louis XIV le françois se répandit dans toute l'Europe [...] Et maintenant cette langue est devenuë un passe-partout [...] toutefois ceux qui viennent les derniers, surpassent quelquefois leur prédécesseurs [...] Ces beaux jours de notre littérature ne sont pas encore venus; mais ils s'approchent. ${ }^{29}$

In einer breit rezipierten Schrift der gleichen Epoche, Paris, le modèle des nations étrangères, ou l'Europe française aus dem Jahr 1777, vertritt Louis-Antoine Caraccioli diese und noch viel weitergehende Positionen ${ }^{30}$. Interessant ist an der Schrift des weitgereisten, aus einer ursprünglich neapolitanischen Familie stammenden Franzosen, der sich konsequent als Europäer versteht, dass er französische Selbsteinschätzungen mit europäischen Fremdeinschätzungen zusammenbringt und daraus sein Bild der kulturellen Vorrangstellung Frankreichs und insbesondere von Paris in Europa entwirft. Zu Beginn des vorigen Jahrhunderts, habe der Kontinent im kulturellen Dunkel gelegen und geradezu auf das Licht gewartet:

Ainsi l'Europe ressembloit à ces nuits sombres où l'on ne découvre que quelques étoiles presqu'imperceptibles, au milieu d'un Ciel nuageux. On attendoit une brillante clarté, sans pouvoir déterminer ni le tems, ni le lieu qui devoient la procurer. ${ }^{31}$

Es ist nach Caracciolis Auffassung Frankreich, welches dieses Licht nach ganz Europa gebracht hat. Den Anfang machte die Epoche Ludwigs des XIV., die das

28 S. 9 f.

30 Vgl. Pierre-Yves Beaurepaire, Le Mythe de l'Europe française au XVIIIe siècle. Diplomatie, culture et sociabilités au temps des Lumières, Paris, Autrement, 2007. Vgl. auch Martine Jacques, „Louis-Antoine Caraccioli: une certaine vision de l'Europe française“, Revue d'histoire littéraire de la France Bd. 114/2014, H. 4, S. 829-842.

31 Paris, le modèle des nations étrangères, ou, L'Europe Françoise, par L'Editeur des lettres du Pape Ganganelli, Venise/Paris, Duchesme, 1777, S. 16. 
Licht verbreitet habe, welches die Medicis vor ihm nur kurzzeitig im Dunkel der Zeiten hatten aufscheinen lassen („Le crépuscule que les Médicis avoient fait luire au milieu des ténèbres, reparut [...]“32). Im 18. Jahrhundert werde dieses Werk dann in ganz Europa vollendet, von dessen Bewohnern es heißt:

[...] nous sommes Français, pour le langage, pour les manières, pour les ajustements, pour les lectures, pour les opinions, \& nous ne cessons de l'exprimer dans nos mœurs. Les Etrangers ne pouvaient mieux faire que de se modéler sur la France $[. . .]^{33}$

Die Größe Frankreichs besteht für Caraccioli im Zusammenspiel von ,esprit philosophique‘, ,esprit de société‘, ,mœurs‘ und ,goût‘ der französischen Sprache und Literatur sowie weiteren Parametern, die der Autor in den einzelnen Kapiteln analysiert. Dabei verhehlt Caraccioli seine Beurteilungskriterien nicht: Dass Europa nunmehr ein rationales Fundament besitzt, verdanke es vor allem Descartes: „,...] grâce à Descartes, tous les Européens ont une Philosophie claire \& précise [...]“334 Diese Rationalität sei gepaart mit einer ,convivialité‘ und ,légèreté‘ der französischen Lebensweise, die sich ebenfalls in ganz Europa bemerkbar mache:

Il n'est pas donné à tous les hommes d'avoir cet esprit liant \& facile, qui gagne la confiance, \& qui plaît dans tous les pays. [...] Les Européens, presque tous sur la réserve, ne sont devenus communicatifs, que depuis qu'ils prirent les manières Françaises..$^{35}$

Die Mischung aus Rationalität und ,leichtem‘, ,verbindendem Geist‘ ergibt für Caraccioli jenen „esprit philosophique“, der den gesamten Kontinent in einem friedlichen Miteinander unter Wahrung der Freiheit seiner Bürger und in Konzentration auf die Wahrhaftigkeit der Geschichtsbetrachtungen vereine:

C'est à cet esprit Philosophique, cet esprit bien entendu, qu'on doit l'amour général qu'on a pour la paix, l'extinction de toutes les haînes qu'excitoit la diversité des religions, la liberté des Citoyens, le courage d'écrire l'Histoire avec vérité [... $]^{36}$

Die besonders in der zweiten Hälfte des 18. Jahrhunderts in Deutschland im Zuge der Entdeckung der eigenen Kultur geltend gemachte Oberflächlichkeit der französischen Zivilisation wird von Caraccioli anthropologisch ins Positive gewendet: Da die Natur des Menschen inkonstant und wechselhaft ist, ist die franzö-

32 S. 19.

33 S. 357.

34 S. 76.

35 S. 84.

36 S. 80 . 
sische Lebensweise umso natürlicher, der menschlichen Lebensweise angemessener und damit vorbildlich:

[...] cette légèreté qu'on reproche aux Francais, \& qui, sans changer leurs constitutions \& et leurs loix, change leurs modes, \& diversifie leurs plaisirs, leur a mérité l'avantage d'avoir beaucoup d'imitateurs. On aime en général le mouvement, \& cela est conforme à notre cœur \& à notre esprit, dont les affections \& les idées sont dans un flux et reflux continuel: de sorte qu'on peut dire que l'homme par sa nature est plutôt volubile que constant. ${ }^{37}$

Caraccioli resümiert seine Beschreibung der kulturellen Vorrangstellung Frankreichs mit dem Satz: „Jadis tout étoit Romain, aujourd'hui tout est Francais.“38 Wie der Titel seines Buchs anzeigt, fokussiert er die europäische Kultur zudem ganz auf die Hauptstadt Paris.

Die Vorstellung von der Universalität der französischen Kultur und der damit verbundenen Größe Frankreichs wird auch in der Folgezeit vom 19. Jahrhundert bis weit ins 20. Jahrhundert hinein bedeutsam bleiben, allerdings mit einer Akzentverschiebung: Im Zuge der Herausbildung der Nationalstaaten im 19. Jahrhundert besinnen sich die einzelnen Länder stärker auf ihre eigene Kultur, allein schon deshalb, weil die Existenz der jeweiligen Nation an eine die Gemeinschaft verbindende Sprache gebunden ist, deren Verbreitung man durch politische Maßnahmen auf den eigenen Territorien erst vollständig durchsetzen muss. Insbesondere in Deutschland etabliert sich die Vorstellung von einer ,Kulturnation', die französischen Vorstellungen von der Zivilisation und ihrer Universalität diametral entgegengesetzt ist ${ }^{39}$. Frankreich bleibt jedoch für die meisten europäischen Länder und darüber hinaus der Maßstab der Zivilisation, da ihm durch die Einführung der Menschenrechte im Zuge der Revolution, die von Napoleon nach ganz Europa getragen werden, erneut eine Vorrangstellung zukommt. Diese Vorrangstellung wird nun allerdings - wie schon bei Caraccioli angedeutet - zunehmend Paris zugeschrieben, in den Worten Walter Benjamins der ,Hauptstadt des 19. Jahrhunderts'. Schon Goethe hatte kurz nach der Revolution in Hermann und Dorothea (1797) den neuen Universalismus der Menschenrechte mit der Stadt Paris in Verbindung gebracht:

Schau'ten nicht alle Völker in jenen dringenden Tagen

Nach der Hauptstadt der Welt, die es schon so lange gewesen,

Und jetzt mehr als je den herrlichen Namen verdiente?

(VI, V. 14-16)

37 S. 262.

38 S. 3. Zur kulturellen Vorherrschaft Frankreichs in Europa siehe auch Louis Réau, L'Europe française au siècle des Lumières (L'Evolution de l'humanité), Paris, Albin Michel, 1938.

39 Dazu siehe weiter unten, S. 63 f. und 66-68. 
Die Stadt Paris wird in der Folgezeit auch durch ihre architekturalen Neuerungen wie z. B. die in der modernen Stahlbauweise erstellten Passagen und durch ihre mit dem Ziel einer urbanistischen Transparenz angelegten städtebaulichen Entwicklungen, die die mittelalterliche Stadt hinter sich lassen, zum Inbegriff des gesellschaftlichen Fortschritts. Als zentrales Beispiel für diese Entwicklung steht die große ,exposition universelle' von 1867: Sie hat - deutlich inspiriert von der Encyclopédie raisonnée - versucht, möglichst alle Bereiche menschlicher Arbeit, des sozialen Zusammenlebens, der Künste und der Wissenschaften auf einem Ausstellungsgelände zusammenzubringen. In der Mitte des Ausstellungsgeländes auf dem champ de mars baut der Architekt Jean Baptiste Krantz ein ovales Kolosseum, welches wie ein Globus die Zivilisation der gesamten Welt symbolisieren soll. Das Konzept der Pariser Ausstellung zielt vor allem auf ,grandeur' und ,universalité‘. Im Dekret zur Ankündigung der Ausstellung von 1863 des verantwortlichen Ministeriums heißt es: „1. Qu'une exposition ait lieu à Paris en 1867 ; 2. qu'elle soit plus complètement universelle que les précédentes [...]“40 Im offiziellen Katalog der Ausstellung wird der Leser und Besucher aufgefordert, den „,caractère de grandeur“ zur Kenntnis zu nehmen. ,Universalité‘ und ,grandeur‘ basieren hier auf einer wirtschaftlichen und politischen Vorstellung: Die Ausstellung wird historisch auf ähnliche Veranstaltungen im antiken Rom unter den Cäsaren zurückgeführt, die mit ihrer Schau der unterschiedlichen Zivilisationen die Beherrschung und Assimilation der dem Reich angehörenden Völker präsentieren wollten. Die Weltausstellung von 1867 hat in der Nachfolge solcher Präsentationen das Ziel, die Staaten Europas in einer wohlwollenden wirtschaftlichen und politischen Rivalität zusammenzuführen:

L'Angleterrre et la France ont seules réussi jusqu'ici à attirer alternativement le concours de tous les pays à leurs expositions [...] qui ont rapproché par la mutualité des intérêts deux peuples divisés jusque là par la politique.

Espérons que Vienne et Berlin se piqueront d'émulation vis-à-vis de Paris et de Londres; et que de cette émulation hospitalière naîtra une plus grande intimité d'intérêts et d'idées, qu'on a vainement demandée jusqu'à ce jour à la diplomatie. ${ }^{41}$

Die Stätte der Ausstellung und ihre „grandeur qu'on voudra bien reconnaître“ sollen den Führungsanspruch Frankreichs im Europa einer solchen „émulation hospitalière des peuples“ markieren.

Diese Narrative gehen unter anderem auf Victor Hugo zurück. Anlässlich der Weltausstellung regt Hugo die Herausgabe eines besonderen Reiseführers für die

40 François Ducuing, Exposition universelle de 1867 illustrée. Publication internationale autorisée par la commission impériale, 2 Bde. Paris, Bureau d’abonnements, 1867, Bd. 1, S. 2.

41 S. 3. 
zu erwartenden Besucher an, in dem die bekanntesten Schriftsteller und Wissenschaftler der Zeit ihre Eindrücke der Einrichtungen und Bauwerke der Stadt beschreiben. Er veröffentlicht diesen Führer in guter Tradition der Kunst des Impliziten unter dem doppeldeutigen Titel: Paris guide. In seiner Einleitung entwickelt Hugo im großen Stil eine Mythologie von Paris, welches ihm als Hauptstadt eines globalisierten Europa erscheint. Es handelt sich genau genommen um eine regelrechte Utopie der Globalisierung, in der Paris den Mittelpunkt bildet: „Au vingtième siècle, il y aura une nation extraordinaire. Cette nation sera grande, ce qui ne l'empêchera pas d'être libre. “42 In dieser europäischen Gesellschaft mit einer gemeinsamen Sprache stellt Frankreich für ihn das humanitäre Gravitationszentrum dar:

La nation centrale d'où ce mouvement rayonnera sur tous les continents sera parmi les autres sociétés ce qu'est la ferme modèle parmi les métairies. Elle sera plus que nation, elle sera civilisation; elle sera mieux que civilisation, elle sera famille. [...] Cette nation aura pour capitale Paris, et ne s'appellera point la France; elle s'appellera l'Europe. [...] au vingtième siècle, et, aussi aux siècles suivants, plus transfigurée encore, elle s'appellera l'Humanité. ${ }^{43}$

Paris hat für Hugo die Nachfolge der großen Städte der Antike angetreten. Die Stadt verkörpere das Wahre, das Schöne und - nota bene! - das Große:

Jerusalem, Athènes, Rome. Les trois villes rhythmiques. L'ideal se compose de trois rayons: Le Vrai, le Beau, le Grand. De chacune de ces trois villes sort un de ces trois rayons. A elles trois, elles font toute la lumière. Jerusalem dégage le Vrai. C'est là qu'a été dite par le martyr suprême la suprême parole: Liberté, Égalite, Fraternité. Athènes dégage le Beau. Rome dégage le Grand. Paris est la somme de ces trois cités. Il les amalgame dans son unité. ${ }^{44}$

Die Stadt wird zum Fixpunkt der modernen Zivilisation und damit selbst zu einem Thema der Erzählliteratur und der Lyrik, zwei Genera, in denen Frankreich erneut europaweit literarische Maßstäbe setzt. Es entsteht der Mythos von Paris, der bis in die sechziger Jahre des 20. Jahrhunderts Schriftsteller, Künstler und Musiker angezogen hat. Pascale Casanova hat gezeigt, dass sich allen politischen Nationalismen und nationalen Abgrenzungen zum Trotz im Bereich der Literatur und Kultur jener Universalismus erhält und auf Paris fokussiert, den die französische Zivilisation stets für sich reklamiert hatte: „Paris est ainsi devenu [...] la capitale de l'univers littéraire, la ville dotée du plus grand prestige littéraire du

42 Victor Hugo, „Introduction”, dans: Paris guide par les principaux écrivains et artistes de la France, 2 parties, Paris, Librairie internationale, 1867, part. 1, S. I-XLIV, hier: S. I.

43 S. IIIf.

44 S. XXf. 
monde.“ ${ }^{45}$ In Paris bildet sich ein ,champ littéraire‘ heraus, der den Schriftstellern und Künstlern, die aus der ganzen Welt dorthin kommen, ein Umfeld bietet, die unterschiedlichsten Rollen zu besetzen. Casanova folgt Paul Valéry, der 1931 in seinem Essay Fonction de Paris festgestellt hatte:

Il est d'abord à mes yeux la ville la plus complète qui soit au monde, car je n'en vois point où la diversité des occupations, des industries, des fonctions, des produits et des idées soit plus riche et mêlée qu'ici. Être à soi seule la capitale politique, littéraire, scientifique, financière, commerciale, voluptuaire et somptuaire d'un grand pays; en représenter toute l'histoire; en absorber et en concentrer toute la substance pensante aussi bien que tout le crédit et presque toutes les facultés et disponibilités d'argent, - et tout ceci, bon et mauvais pour la nation qu'elle couronne, c'est par quoi se distingue entre toutes les villes géantes, la Ville de Paris. [...] Ce Paris, dont le caractère résulte d'une très longue expérience, d'une infinité de vicissitudes historiques; qui, dans un espace de trois cents ans, a été deux ou trois fois la tête de l'Europe, [...] s'est fait la métropole de diverses libertés et la capitale de la sociabilité humaine. ${ }^{46}$

Paris hat in seiner modernen städtebaulichen Entwicklung und seiner Präsenz der gesamten Künste in Europa endgültig die Nachfolge Roms angetreten.

1930 zeichnet Ernst Robert Curtius in seiner Schrift über die Kultur Frankreichs die Entwicklung von Paris hin zu dieser Rolle seit dem Mittelalter nach und hält fest:

Das antike Rom und das moderne Paris sind die beiden einzigen Beispiele dafür, daß die politische Hauptstadt eines großen Staates der Mittelpunkt seines gesamten nationalen und geistigen Lebens geworden ist und daß sie darüber hinaus für die ganze bewohnte Welt die Bedeutung des kosmopolitischen Kulturzentrums erlangt hat. [...] Nur in Paris empfindet man, wie in Rom, ein Universales von Humanität, von dem man umgeben ist. ${ }^{47}$

Curtius zeigt auch, dass in Frankreich die Entstehung der Nation nicht zu einer Verdrängung des Universalismus und zur Höherschätzung kultureller Partikularitäten führt ${ }^{48}$. Nach französischem Selbstverständnis verschafft der Nationalismus im Gegenteil den Ansprüchen des Universalismus eine breite Geltung. Dies gilt im Besonderen für den in der Französischen Revolution errungenen Anspruch der Gleichheit aller Bürger. So hatte der Gleichheitsanspruch zur Folge, durch ei-

45 Pascale Casanova, La République mondiale des Lettres, Paris Du Seuil, ${ }^{2} 2008$ (11999), S. 47.

46 In: Paul Valéry, Regards sur le monde actuel, Paris, Stock, Delamain et Boutellau, 1931, S. 43-45, hier: S. $44 \mathrm{f}$.

47 Die Französische Kultur. Eine Einführung, Berlin/Leipzig, 1930, S. 151.

48 Vgl. S. 7. Vgl. auch Joseph Jurt, Sprache, Literatur und nationale Identität. Die Debatten über das Universelle und das Partikuläre in Frankreich und Deutschland (mimesis. 58), Berlin/Boston, De Gruyter, 2014, S. 180. 
ne zentralistisch gesteuerte Schulbildung im Innern des Landes alle Bürger mit einer ähnlichen Kultur auszustatten. Aus diesem als universell verstandenen Bildungsauftrag leitet sich wiederum das Postulat ab, die Errungenschaften der Zivilisation auch nach außen zu tragen: Spätestens mit der Dritten Republik mündet der von Aufklärern wie dem Marquis de Condorcet entworfene Anspruch auf Zivilisierung auch der ,Naturvölker‘ in das Programm der ,mission civilisatrice“ und ihrer speziell durch Frankreich praktizierten Politik der ,assimilation‘. Der Gleichheitsgrundsatz des ,rendre semblable، führt zu einem kolonialistischen Diskurs, der von der grundsätzlichen Einheit und Gleichheit aller Menschen ausgeht. Vorbereitend für diese Ideologie war der Mythos vom ,Guten Wilden', der in den Essais Michel de Montaignes aufkommt, in der Aufklärung weite Verbreitung findet und die Wurzeln für eine Zivilisierung der nicht-zivilisierten Völker im 19. Jahrhundert legt. Das auf Paris zentrierte Frankreich exportiert auf diese Weise seine Sprache und Kultur in große Teile der Welt und sieht sich durch seine zivilisatorische Mission in seiner, grandeur' bestätigt. Der universalistischen Vorstellung der französischen Zivilisation und ihrem inhärenten Bildungsauftrag liegt die weitgehend unhinterfragte Vision einer sich zum Fortschritt hin entwickelnden Geschichte zugrunde, die Europa und stellvertretend Frankreich als Endpunkt der historischen Entwicklungen ansieht.

Durch den deutsch-französischen Krieg von 1870/1871 sowie die beiden Weltkriege wird diese Anschauung jedoch massiv erschüttert. De Gaulles Politik der Nachkriegsrepublik, die ,grandeur de la France“ wiederherzustellen, geht von der traumatischen Erfahrung der Kriegsniederlage von 1940 aus. Frankreich gehörte zwar letztlich zu den Siegermächten, hatte jedoch nicht aus eigener Kraft gesiegt. Über eine besonders aktive und kostspielige Kulturpolitik, die zu einem bevorzugten Instrument der Außenpolitik wird, versucht de Gaulle Domänen zurückzugewinnen, die international an die angelsächsische Kultur verlorengegangen waren ${ }^{49}$. Diese Kulturdiplomatie kann jedoch nur bedingt Erfolge verzeichnen, zumal sie in die Phase vom Ende des französischen Kolonialismus fällt, die Frankreichs Einfluss in der Welt stark einschränkt. Die postkolonialen Debatten über die ideologischen Verblendungen der ,mission civilisatrice ' tun darüber hinaus ihr Übriges. Das letzte große Gefecht im Namen der ,exception culturelle‘, der kulturellen Sonderstellung, führt Frankreich gegen den Überhand nehmenden Einfluss der amerikanischen Film- und Musikindustrie. Mit Unterstützung Deutschlands und der meisten EU-Staaten hat das Land versucht, in den GATTVerhandlungen in Uruguay 1986-1994 sowie in den Verhandlungen zu einem Frei-

49 Vgl. dazu Marc Fumaroli, L'État culturel. Essais sur une religion moderne, Paris, Editions de Fallois, 1991. 
handelsabkommen mit den USA den Bereich der Kultur aus den Mechanismen von ökonomischem Angebot und Nachfrage auszuklammern und unter staatlich-protektionistische Aufsicht zu stellen. Aus Rücksicht auf die anderen europäischen Staaten, die man bei dieser Aufgabe als Verbündete braucht, spricht man nicht länger von der ,exception culturelle‘ Frankreichs, sondern von der ,diversité culturelle‘ Europas.

Die Erkenntnis, dass die französische Kultur im Zeitalter der Globalisierung nur noch eine Kultur unter vielen ist, führt in Frankreich zu regelrechten traumatischen Erfahrungen und zu geradezu verzweifelten Versuchen, eine wie auch immer geartete kulturelle ,identité française‘ zu umschreiben. Davon zeugt das in diesem Kontext stark diskutierte, bereits im vorigen Kapitel erwähnte Buch von Zemmour Melancholie française (2010). Zemmour sieht Frankreich wie zahlreiche Autoren vor ihm als Nachfolgerin des römischen Reichs mit dem friedfertigen Anspruch, sein universalistisches, egalitäres Menschenbild in den Nachbarstaaten Europas durchzusetzen. Für Zemmour beginnt die Krise der französischen Identität mit Napoleons Niederlage 1815. Der letzte Versuch einer Rettung des Projekts, Europas Kultur den universalistischen Ansprüchen der französischen Zivilisation anzupassen, war für ihn dann die Europapolitik de Gaulles, der den Kontinent mit einer entsprechenden Kulturpolitik unter die Führung eines starken, an seine ,grandeur` anknüpfenden Frankreich zu bringen versuchte. Mit dem Zusammenbruch der osteuropäischen Staaten wurde jedoch aus der europäischen Einheit allmählich ein Staatenbund, der Deutschland einen gegenüber Frankreich gestiegenen Einfluss gesichert hat. Aus der Diskussion über den Bedeutungsverlust der französischen Zivilisation ragt neben Zemmour vor allem der konservative Intellektuelle Alain Finkielkraut heraus, insbesondere mit seinem Buch L'Identité malheureuse (2013). Finkielkraut wendet sich gegen eine groß angelegte Dekulturation insbesondere des französischen Schulwesens, die er wesentlich auf die Dominanz ökonomischen Denkens zurückführt, welches in der Gegenwart nicht nur in Frankreich alle Bereiche des Lebens durchsetzt. Frankreich habe seine Eliten verloren gemeint sind Eliten wie die Aristokratie des 17., die Aufklärer des 18. und die Schriftsteller und Intellektuellen des 19. und 20. Jahrhunderts - und mit ihnen seinen Anspruch auf eine kulturelle Ausnahmestellung. Finkielkraut beklagt den kulturellen Verfall der Tradition in einem Europa, welches durch den Kosmopolitismus der globalen Zeit in ein Zeitalter der ,Nachidentität“ („,̂age postidentitaire“50) eingetreten sei. Europas logozentrische Tradition des rationalistisch-kritischen Zerlegens jedweder Identität habe die ,,autorité de la coutume“"51 hinter sich gelassen. In

50 L'Identité malheureuse, Paris, Stock, 2013, S. 133.

51 S. 135 
diesem Kontext der Klage über den Verfall der europäischen (französisch geprägten) Zivilisation Europas beklagt er u. a. den Verlust der für Frankreich typischen ,galanterie‘, die wesentlich auf der ,politesse‘ des indirekten Sprechens beruht. Er macht dies an einem interkulturellen Beispiel aus Voltaires Roman Candide ou l'optimisme (1759) fest, in dem der französische Philosoph den französischen Umgang miteinander - im Sinne von ,conversio“ - vom deutschen abgrenzt:

Candide, qui était né en Allemagne et qui, comme son nom l'indique, avait le cœur sur les lèvres, ne connaissait pas cet usage [= la galanterie]. Alors quand une dame de qualité le reçoit, dans son salon parisien, et qu'elle lui demande, après avoir écouté le récit de ses mésaventures, s’il aime toujours mademoiselle Cunégonde de Thunder-ten-tronckh, il dit naïvement la vérité qui tient en un mot: oui. Ce qui lui attire cette galante réprimande: „Vous me répondez comme un jeune homme de Westphalie; un Français m'aurait dit: Il est vrai que j’ai aimé mademoiselle Cunégonde, mais, en vous voyant, madame, je crains de ne la plus aimer." ${ }^{52}$

Für Finkielkraut ist die situationsbedingt richtige Antwort nicht die direkte Aussprache der Wahrheit, sondern die indirekte Ansprache per Kompliment, ein traditionelles ziviles Verhalten, welches im ,âge postidentitaire‘ der Vergangenheit angehört.

Den Büchern Zemmours und Finkielkrauts liegt die letztlich unausgesprochene Gewissheit zugrunde, dass es ein Frankreich dieser kulturellen Ausnahme und damit der ,grandeur“ nicht mehr gibt, weil ,Identitäten' nicht mit stabilen, unveränderlichen Kategorien zu erfassen, sondern immer historischen Veränderungen unterworfen sind. Diese unverrückbaren historischen Entwicklungen lassen sich auch nicht durch den jüngsten Versuch des Präsidenten Emmanuel Macron ungeschehen machen, der über eine stark symbolisch ausgerichtete Politik versucht, Frankreich seine, grandeur‘ wiederzugeben.

\subsection{Die Bewusstwerdung einer eigenständigen Kultur in Deutschland und die französische Wahrnehmung dieser Eigenständigkeit als ,les deux Allemagnes`}

Anders als die französische Zivilisation, die aufgrund der schon im Mittelalter vorhandenen zentralistischen Strukturen des Landes über Jahrhunderte hinweg definierbare Konturen aufweist, findet die Besinnung auf die Eigenheiten der deutschen Kultur mit einer erheblichen historischen Verspätung verstärkt erst im

52 L'Identité malheureuse, S. 78. 
Vorfeld des Einigungsprozesses in Deutschland im 19. Jahrhundert statt. Die Bewusstwerdung der Bedeutung dieser Kultur beginnt in der Aufklärung, und das vor allem in Abgrenzung von der französischen Zivilisation. $\mathrm{Zu}$ den Eigenheiten der deutschen Kultur finden sich allerdings auch schon zur Zeit der Renaissance erneut in den Épithètes von La Porte einige bemerkenswerte Einträge. Unter dem Eintrag ,Allemagne“ wird Folgendes verzeichnet:

Superbe, guerrière, barbare, puissante, froide, prompte au tambourin, rebelle, valeureuse, indomtable.

Incontinent après le déluge l'Allemagne fut appellée Teutonie qui est son premier nom: Depuis par les Romains Germanie, de laquelle pour la variété qui est entre les auteurs tant anciens que modernes il est malaisé de décrire les bornes et limites. ${ }^{53}$

Die Deutschen sind demzufolge ein Volk von Kriegern. Ihr Charakteristikum ist ihre rebellische, unkalkulierbare Art, Garant ihrer Unbezwingbarkeit. So ungreifbar wie diese Krieger ist auch ihr Territorium (,incontinent“), dessen Grenzen nicht $\mathrm{zu}$ beschreiben sind. Suggestiv ist vor allem die konnotative Verbindung zwischen den Deutschen und der scheinbar beiläufig eingeführten Zeitangabe ,Sintflut‘, die festlegt, dass die beobachteten Charakteristika seit jeher Gültigkeit besitzen. Die Zeitbestimmung suggeriert jedoch auch, dass von den Deutschen eine quasi unaufhaltsame Bedrohung wie eine Naturgewalt ausgeht. La Porte verweist in einem zweiten Artikel über die Deutschen („Allemands“) für eine weiterführende Lektüre auf die Cosmographia (1550) des rheinischen Humanisten und Universalgelehrten Sebastian Münster. Im Wesentlichen bezieht er jedoch seine Kenntnisse über die Deutschen aus der Schrift Germania (98 n. Chr.) des römischen Historikers Publius Cornelius Tacitus, die seit 1426 in der Renaissance rezipiert wird und auf die auch das dritte Buch der Cosmographia „Von dem Teutschen Land“ fortwährend rekurriert. Der römische Historiker, der sich mit den Deutschen befasst, um der Dekadenz seiner Landsleute einen Spiegel vorzuhalten, beschreibt die Germanen vor allem als Krieger, deren Freiheitsdrang die Römer das Fürchten gelehrt habe („Germanorum libertas“54). Die in ihren unterschiedlichen Stämmen beschriebenen Bewohner des Nordens leben laut Tacitus in einer geographisch gestaltlosen Landschaft mit rauem Klima und äußerst betrüblichen Behausungen ${ }^{55}$ im Einklang mit der sie umgebenden Natur.

$53 \mathrm{http} / / /$ www.preambule.net/epithetes/a/allemagne.html.

54 Vgl. das Kap. XXXVII über die Kimbern als Schrecken der Römer (Tacitus, De origine et situ Germanorum, http://www.latein-imperium.de/include.php?path=content\&mode=print\& contentid=106).

55 So heißt es in Kap. II: „Wer würde - abgesehen von der Gefahr eines rauen und unbekannten Meeres - entweder Asien, Afrika oder Italien verlassen und dann Germanien aufsuchen, ge- 
Für den Kontext der Betrachtungen über interkulturelle Differenzen zwischen Deutschen und Franzosen ist es nicht entscheidend, dass Hochphasen der deutschen Kultur wie die mittelalterliche Minnedichtung, aus der die ältere germanistische Mediävistik ein europäische Standards setzendes ,Ritterliches Tugendsystem‘ abgeleitet hatte, bei La Porte keinerlei Berücksichtigung finden. Zentral ist hier allein die französische Wahrnehmung des 16. Jahrhunderts, dass die deutschen Nachbarn eher als ein einer Naturgewalt ähnliches, unbeherrschtes und unbeherrschbar ungreifbares Volk ohne genau beschreibbares Territorium sind.

Im Zuge der Herausbildung des deutschen Kultur- und Nationalbewusstseins rücken jedoch ganz andere Kriterien in den Mittelpunkt, die dann auch bei der Wahrnehmung der Deutschen durch Frankreich eine Rolle spielen. Das deutsche Nationalbewusstsein ist wie jedes Nationalbewusstsein ganz besonders an die Entwicklung der Landessprache gebunden, der der preußische König Friedrich II. in der zweiten Hälfte des 18. Jahrhunderts ja noch keine allzu große Bedeutung beigemessen hatte. Doch bereits der zweite Preisträger der Preußischen Akademie bei der Preisfrage „Qu'est-ce qui a fait de la langue Française la langue universelle de l'Europe?“ von 1782, der Stuttgarter Professor Johann Christoph Schwab, war der Auffassung, dass die deutsche Sprache und die deutsche Kultur in Zukunft durchaus eine gewichtige Rolle in Europa einnehmen könnten ${ }^{56}$. In seiner Preisschrift Von den Ursachen der Allgemeinheit der Französischen Sprache und der wahrscheinlichen Dauer ihrer Herrschaft war Schwab zwar der Meinung, dass das Französische vorerst die „Universalsprache von Europa“ ${ }^{57}$ bleiben werde, sieht aber, dass sich diese Situation durchaus ändern könne, sollte die „Cultur der Nation [...] oder die politische Größe derselben herabgewürdiget werden“ ${ }^{\circ 8}$. Die deutsche Sprache wird für ihn aufgrund sprachinterner Komplexitäten wie z. B. der syntaktischen Abweichungen vom ,ordre naturel', der Häufung von Nebensät-

staltlos was seine Landschaft, rau was sein Klima, betrübend was seine Bebauung und seinen Anblick betrifft, außer wenn es seine Heimat wäre?“ („Quis porro, praeter periculum horridi et ignoti maris, Asia aut Africa aut Italia relicta Germaniam peteret, informem terris, asperam caelo, tristem cultu adspectuque, nisi si patria sit?" - De origine et situ Germanorum; http://www.lateinimperium.de/include.php?path=content\&mode=print\&contentid=101\#1).

56 Zur Charakterisierung Schwabs vgl. Jürgen Storost, Langue française - langue universelle? Die Diskussion über die Universalität des Französischen an der Berliner Akademie der Wissenschaften. Zum Geltungsanspruch des Deutschen und Französischen im 18. Jahrhundert (Studien zur Romanistik. 12), Hamburg, Dr. Kovač, ${ }^{2} 2008$ ( ${ }^{1}$ Bonn, Romanistischer Verlag, 1994), S. 227-235. Vgl. auch S. 97.

57 Tübingen, Jacob Friedrich Heerbrandt, ${ }^{2} 1785$ (1784), S. 138. Zu Schwab im Zusammenhang mit der Herausbildung eines deutschen Nationalbewusstseins vgl. auch Jurt, Sprache, Literatur und nationale Identität, S. 89-101.

58 S. $136 \mathrm{f}$. 
zen, der Schwierigkeiten der Deklinationen, „schwerlich jemals die Herrschende in Europa" 59 werden. Sie hat jedoch gleichwohl für Schwab Potential, da sie die „Biegsamkeit des Deutschen Geistes“60 spiegele. Da die Deutschen das „lernbegierigste Volk von Europa“"61 seien, wird ihnen eine Zukunft bescheinigt. Bereits jetzt seien sie mit Philosophen wie Gottfried Wilhelm Leibniz führend in der „speculativen Philosophie“62. Aufgrund ihrer durch die Geschichte bezeugten „Treue und Genauigkeit“63 seien in Europa die „Deutsche(n) (...) am meisten zum Denken aufgelegt“64. Dies führe zu einer Schreibweise, die die Deutschen gegenüber allen anderen europäischen Nationen auszeichne:

Daher die gedrungene und starke Schreibart, die uns vor unsern Nachbarn auf eine so vortheilhafte Art auszeichnet, daher jene männliche und herkulische Charaktere in einigen unserer Schauspiele und Romanen [... $]^{65}$

Schwabs Beschreibung deutscher Stärke in ihrer kulturellen Ausprägung, in der sich von La Porte beschriebene anthropologische Eigenschaften wiederfinden, kehrt dann als Argument zu Beginn des 19. Jahrhunderts wieder.

Aufgrund der mangelnden staatlichen Einheit, die sich zu Beginn des 19. Jahrhunderts auch nicht annähernd abzeichnet, erfolgt die Besinnung auf nationale Tugenden der Deutschen über die Kultur. Dabei steht zunächst erneut die Sprache im Mittelpunkt. Sprachvergleiche mit dem Französischen als der in ganz Europa verbreiteten Sprache werden immer wieder gezogen und fallen nun angesichts des Widerstandes gegen die napoleonische Besetzung weitgehend zugunsten des Deutschen aus. In seiner Schrift Von der Sprachfähigkeit und dem Ursprung der Sprache (1795) geht Johann Gottlieb Fichte davon aus, dass die ursprüngliche Sprache eine Naturkraft darstellt. Die Sprache ist für Fichte ganz pragmatisch gesehen ein Werkzeug, welches der Mensch herausbildet, um die Naturkräfte zu bändigen. Dieses Werkzeug wird im Laufe der Generationen stetig weiterentwickelt. In seinen Reden an die deutsche Nation (1807-1808) bestimmt er dann das Deutsche als eine solche Ursprache, aus der sich die Sprachen der einzelnen germanischen Stämme entwickelt hätten. Das Argument wird benutzt, um den Status des Deutschen zu stärken und den des Französischen zu schwächen. Für Fichte ist das Französische nämlich eine aus dem Lateinischen abgeleitete „neulateini-

59 Ebd.

60 S. 117.

61 Ebd.

62 S. 115.

63 Ebd.

64 S. 129.

65 Ebd. 
sche“ Sprache, und damit minderwertiger als die Ursprache der Deutschen ${ }^{66}$. Die neulateinischen Sprachen befleißigen sich abstrakter Begrifflichkeiten wie „Humanität, Popularität, Liberalität“67, die als „Sinnbilder“ jeden Bezug zu einer natürlichen Sinnlichkeit verloren haben:

Im Umfange deutscher Rede entsteht eine solche Einhüllung in Unverständlichkeit und Dunkel entweder aus Ungeschicktheit oder aus böser Tücke [...] In den neulateinischen Sprachen aber ist diese Unverständlichkeit natürlich und ursprünglich, und sie ist durch gar kein Mittel zu vermeiden, indem diese überhaupt nicht im Besitze irgend einer lebendigen Sprache, woran sie die todte prüfen könnten, sich befinden, und, die Sache genau genommen, eine Muttersprache gar nicht haben. ${ }^{68}$

Fichtes Analyse operiert mit mytho-motorischen Annahmen, die ihrerseits seit langem bekannt sind: Das Deutsche erscheint näher an der sinnlichen Natur als das Französische, das in Künstlichkeit verflacht ist. Die Einführung solch „fremder und römischer Sinnbilder“ wie die genannten Begrifflichkeiten ist für ihn „,künstlich“ und „,würde ihre [= der Deutschen] sittliche Denkart [...] herunterstimmen"69. Französische aristokratische Künstlichkeit und Oberflächlichkeit werden hier im Subtext der Äußerungen deutscher Tugendhaftigkeit und Natürlichkeit gegenübergestellt.

In einer 1814 anonym erschienen Schrift Der Sprach-Gerichtshof oder die französische und deutsche Sprache in Deutschland vor dem Richterstuhl der Denker und Gelehrten heißt es dann gleich zu Beginn, dass die deutsche Sprache in ihrer Entwicklung durch das Französische eher behindert als gefördert worden ist. Der Autor rekurriert auf Zeugnisse von Gelehrten beider Länder und behauptet im Rückgriff auf Fichtes Theorie der Ursprache, dass die deutsche Sprache gegenüber der nur „abgeleitete[n]“ französischen Sprache reicher und energiegeladener sei:

Die deutsche Sprache ist reicher als die französische [...] dadurch, dass die französische Sprache eine abgeleitete, die deutsche aber eine Ursprache ist, die sich durch ihre glückli-

66 Vgl. dazu Johannes Heinrichs, „Nationalsprache und Sprachnation. Die Gegenwartsbedeutung von Fichtes ,Reden an die deutsche Nation“”, in: Klaus Hammacher/Richard Schottky/Wolfgang H. Schrader (Hrsg.), Fichte Studien. Beiträge zur Geschichte und Systematik der Transzendentalphilosophie, Bd. 2: Kosmopolitismus und Nationalidee, Amsterdam, Rodopi B. V., 1990, S. 51-73, hier: S. 54. Vgl. auch Jurt, Sprache, Literatur und nationale Identität, S. 187 f.

67 Johann Gottlieb Fichte, „Vierte Rede: Hauptverschiedenheit zwischen den Deutschen und den übrigen Völkern germanischer Abkunft“, in: Johann Gottlieb Fichtes sämmtliche Werke, 8 Bde., hrsg. von Immanuel Hermann Fichte, Berlin, Veith \& Comp., 1845-1846, Bd. 7, S. 311-327, hier: S. 321.

68 S. 323.

69 S. 321. 
chen Anlagen ganz frei und unbeschränkt durch Ableitung und Zusammensetzungen in's Unendliche fortbilden kann $[. . .]^{70}$

Diese Einschätzung richtet sich erneut gegen die Künstlichkeit und Gleichförmigkeit der französischen Zivilisation. Indem der Verfasser der Individualität der deutschen Sprache, ihrer kraftvollen energiegeladenen Direktheit das Wort redet und den Nachahmungscharakter der französischen Kultur betont, gibt er sich als Vertreter romantisch-moderner Werte und Gegner des Klassizismus zu erkennen und überträgt diese ästhetischen Werte zugleich auf die Nationalcharaktere der beiden Länder:

\begin{abstract}
Die französischen Schriftsteller haben unter sich in Styl und Darstellung die größte Aehnlichkeit. Ursprünglich liegt der Grund davon in der überfeinerten Kultur der Franzosen, oder ihrer überkommenen Höflichkeit - die sie alle gleich färbt, und bei dem Einzelnen den Menschen mehr oder weniger verschleiert. Denn so grell die Nation als Nation hervortritt; so wenig unterscheidet sich der Einzelne von dem Einzelnen. Der Franzose ist sein ganzes Leben hindurch Schauspieler. [...] Daher die Schwäche der Dichter in Charakterzeichnungen; [...] daher die Tonlosigkeit der Sprache, weil der Franzose das Starkausgesprochene haßt; [...] daher [...] sein Festhalten der äußeren Formen, weil ihm Künstlichkeit und übereinkommlicher Anstand mehr gilt als Natur, [...] daher seine Scheu vor dem Kecken, Originellen, Kräftigen, weil alles dies auszeichnet $[\ldots]^{71}$
\end{abstract}

Demgegenüber ist es der deutschen Sprache möglich, ein „ursprünglich tieferes Gefühl“" zum Ausdruck zu bringen und ,aus der Fülle angeborner Kraft“ zu schöpfen $^{72}$. Am Ende seiner Schrift entwirft der Autor die Vision, dass sich die deutsche Sprache „von dem einen Ende von Europa zum andern ausbreiten wird.“73

Nun führt die Besinnung auf eine autochthone deutsche Kultur jedoch auch jenseits der Reflexion der Sprache statt. Vor allem zwei - erneut aus Frankreich stammende - Anschauungsmuster sind es, die Conrad Wiedemann für die Besinnung auf einen deutschen Nationalcharakter verantwortlich gemacht hat. Zum einen regt Montesquieus Theorie vom ,esprit des nations' aus seiner Schrift De l'esprit des lois (1748) dazu an, jenseits universalistischer Muster über die Spezifika der jeweiligen Nation nachzudenken. Montesquieus klimatheoretischer Ansatz verfolgt den Gedanken, dass die kulturellen Gegebenheiten einer Nation an die spezifischen geographischen und kulturellen Umstände gebunden sind, unter denen sie entstehen. Zum anderen ist es Voltaires Anschauung vom ,esprit de

70 Der Sprach-Gerichtshof oder die französische und deutsche Sprache in Deutschland vor dem Richterstuhl der Denker und Gelehrten, Berlin, Maurersche Buchhandlung, 1814, S. 7.

71 S. $20 \mathrm{f}$.

72 S. 26.

73 S. 77. 
temps‘ aus seiner Schrift Le siècle de Louis XIV (1751), die dazu auffordert, die genauen zeithistorischen Umstände in Betracht zu ziehen ${ }^{74}$. Mit der gegen Ende der Aufklärung immer dominanteren Episteme der ,Tiefenstruktur‘, des historischen Denkens in die Tiefe, das Michel Foucault als neues Paradigma modernen Denkens identifiziert ${ }^{75}$ sowie der seinerzeit von Reinhart Koselleck beschriebenen zunehmenden Rede von ,der Geschichte in der von ihm so genannten Sattelzeit um $1770^{76}$, entstehen dann nationale Identitätskonzepte in Deutschland jenseits universalistischer Anschauungsmuster. Das Modell dieses Denkens ist das der organologischen Entwicklung. Der Schweizer Romanist Joseph Jurt zeigt, inwieweit Justus Möser in seiner Schrift Über die deutsche Sprache und Literatur von 1781 einer stets nur relativen Schönheit das Wort redet ${ }^{77}$ und inwieweit die organizistische Kulturauffassung Johann Gottfried Herder dazu führt, im Namen der neu entstehenden Geschichtsphilosophie die klassische Auffassung der Kultur als Erfüllung zeitloser Normen in Frage zu stellen und daraus die Legitimität jeweils partikulärer Kulturentwicklungen abzuleiten ${ }^{78}$. Gegen die von den französischen aristokratischen Eliten behauptete ,exception culturelle‘ entsteht eine Besinnung auf die archaischen Kulturen des Nordens. Deren Vielfalt wird dem Alleinvertretungsanspruch der universalistisch angelegten französischen Zivilisation entgegengestellt. Den nordischen Kulturen wird eine größere Naturverbundenheit und damit Energie unterstellt, die der eingespielten und in Regeln festgefahrenen Zivilisation des Nachbarlandes überlegen zu sein scheint.

Ein Auslöser für die Wahrnehmung der deutschen Nation als Kulturnation in Frankreich ist die deutsche Romantik und ihre tiefe Naturverehrung, die sich unmittelbar auf die Rheinlandschaft an der Grenze zu Frankreich richtet. Mit Friedrich Schlegels Begeisterung für die wilde Schönheit des Mittelrheintals, die er im Bericht seiner Reise nach Paris dokumentiert, sowie mit Clemens Brentanos und Achim von Arnims Wanderung am Rhein im Jahre 1802 wird die deutsche Grenz-

74 Conrad Wiedemann: „Deutsche Klassik und nationale Identität. Eine Revision der Sonderwegs-Frage“, in: Wilhelm Vosskamp (Hrsg.): Klassik im Vergleich. Normativität und Historizität europäischer Klassiken. Stuttgart, Metzler 1993, S. 541-569, hier: S. 553. Vgl. auch Jurt, Sprache, Literatur und nationale Identität, S. 107 f.

75 Les Mots et les choses. Une archéologie des sciences humaines (Bibliothèque des sciences humaines), Paris, Gallimard, 1966, S. 324.

76 „Einleitung“, in: Otto Brunner/Werner Conze/Reinhart Koselleck (Hrsg.), Geschichtliche Grundbegriffe. Historisches Lexikon zur politisch-sozialen Sprache in Deutschland, Stuttgart, Klett-Cotta, 1972, Bd. 1, S. XV. Vgl. auch ders., „Das 18. Jahrhundert als Beginn der Neuzeit“, in: Reinhart Koselleck, Epochenschwelle und Epochenbewußtsein (Poetik und Hermeneutik. 12), München, Wilhelm Fink, 1987, S. 269-282, bes. S. 278-282.

77 Sprache, Literatur und nationale Identität, S. 114.

78 S. $116 \mathrm{f}$. 
landschaft zu Frankreich als ein den Deutschen ureigener Naturraum mythisiert. In dieser Zeit beginnt man in Frankreich wahrzunehmen, wie unterschiedlich die zivilisatorischen Einstellungen und kulturellen Prägungen von Franzosen und Deutschen sind. Es ist Madame de Staëls Buch über Deutschland, De l'Allemagne (1810), mit dem in Frankreich das Interesse am Land jenseits des Rheins geweckt wird. Bei aller Differenziertheit ihres auf eigenen Beobachtungen basierenden Deutschlandbuches tauchen die Beurteilungen La Portes aus dessen Epithètes über Deutschland hier erneut auf. Auch Mme de Staël beklagt den mangelnden Zentralismus des regional strukturierten Deutschlands. Auch sie geht davon aus, dass Frankreich in Europa die herausragende Zivilisation verkörpert:

Les nations dont la culture intellectuelle est d'origine latine, sont plus anciennement civilisées que les autres; elles ont pour la plupart hérité de l'habile sagacité des Romains, dans le maniement des affaires de ce monde. ${ }^{79}$

Anders als Maurice de la Porte weiß sie die deutsche Kultur jedoch durchaus zu würdigen. Diese resultiert für sie aus der christlichen Religion und dem mit ihr verbundenen mittelalterlichen Rittertum, welches Deutschland ohne den Einfluss der römischen Zivilisation auf direktem Weg angenommen habe. Daraus entsteht für Mme de Staël eine ganz andere mentale Einstellung als in Frankreich, weil die Deutschen zutiefst in archaische, mittelalterliche Anschauungen verstrickt sind, die sich zudem emotional auf die damit verbundenen Schauplätze und Landschaften fokussieren:

Les nations germaniques ont presque toujours résisté au joug des Romains; elles ont été civilisées plus tard, et seulement par le christianisme; elles ont passé immédiatement d'une sorte de barbarie à la société chrétienne: les temps de la chevalerie, l'esprit du moyen âge sont leurs souvenirs les plus vifs; et quoique les savants de ces pays aient étudié les auteurs grecs et latins, plus même que ne l'ont fait les nations latines, le génie naturel aux écrivains allemands est d'une couleur ancienne plutôt qu'antique; leur imagination se plaît dans les vieilles tours, dans les créneaux, au milieu des guerriers, des sorcières et des revenants; et les mystères d'une nature rêveuse et solitaire forment le principal charme de leur poésies. ${ }^{80}$

Deutsche und Franzosen stehen sich somit, was ihre mentalen Einstellungen angeht, geradezu diametral gegenüber: „On pourrait dire avec raison que les Français et les Allemands sont aux deux extrémités de la chaîne morale [...] "81 Anders als das seit der Römerzeit zivilisierte Frankreich ist Deutschland noch ein Raum einer weitgehend von der Zivilisation unberührten Natur:

79 De l'Allemagne, Paris, Firmin Didot Frères, 1852, S. 9.

80 S. 9 f.

81 S. 10. 
La multitude et l'étendue des forêts indiquent une civilisation encore nouvelle: le vieux sol du Midi ne conserve presque plus d'arbres, et le soleil tombe à plomb sur la terre dépouillée par les hommes. L'Allemagne offre encore quelques traces d'une nature non habitée. Depuis les Alpes jusqu'à la mer, entre le Rhin et le Danube, vous voyez un pays couvert de chênes et de sapins, traversé par des fleuves d'une imposante beauté, et coupé par des montagnes dont l'aspect est très-pittoresque; mais de vastes bruyères, des sables, des routes souvent négligées, un climat sévère, remplissent d'abord l'âme de tristesse; et ce n'est qu’à la longue qu'on découvre ce qui peut attacher à ce séjour. ${ }^{82}$

Aus diesen Bedingungen sowie der noch durch ein mittelalterliches Umfeld geprägten Kultur der Deutschen leitet Mme de Staël eine den französischen Beobachter verunsichernde Unzugänglichkeit, weil voller in sich gekehrter Tiefe, der Bewohner rechts des Rheins ab.

Les débris des châteaux forts, qu'on aperçoit sur le haut des montagnes, les maisons bâties de terre, les fenêtres étroites, les neiges qui, pendant l'hiver, couvrent des plaines à perte de vue, causent une impression pénible. Je ne sais quoi de silencieux, dans la nature et dans les hommes, resserre d'abord le cœur. ${ }^{83}$

In Deutschland sei die Vermittlung von Zivilisation und Natur noch nicht an ihrem Endpunkt angelangt:

On est frappé sans cesse, en Allemagne, du contraste qui existe entre les sentiments et les habitudes, entre les talents et les goûts: la civilisation et la nature semblent ne s'être pas encore bien amalgamées ensemble. ${ }^{84}$

Mme de Staël argumentiert auf der Basis der klimatheoretischen Erwägungen Montesquieus. Ist die Entwicklung der römisch-französischen Zivilisation für sie ein rationaler Prozess, der mit dem Absolutismus neue, immer rationalere Dimensionen gewonnen hat, so scheint für sie die Kultur der Deutschen eher als ein Produkt der Natur. Mme de Staël versteigt sich zu der Behauptung, man habe den Eindruck, dass der Rhein und nicht der Mensch in Deutschland für die Akkulturation verantwortlich sei:

Les contrées qu'il (le Rhin) traverse paraissent tout à la fois si sérieuses et si variées, si fertiles et si solitaires, qu'on serait tenté de croire que c'est lui-même qui les a cultivées, et que les hommes d'à present n'y sont pour rien. Ce fleuve raconte, en passant, les hauts faits des temps jadis, et l'ombre d'Arminius semble errer encore sur ces rivages escarpés. ${ }^{85}$

82 S. 13.

83 Ebd.

84 S. 20.

85 S. 14. 
Man muss sich allerdings fragen, ob Mme de Staël mit ihren Beobachtungen letztlich nicht genau jene Mythisierung der deutschen Natur reproduziert, die mit der beginnenden deutschen Romantik zu Beginn des 19. Jahrhunderts immer stärker verbreitet wurde. Auf der einen Seite empfiehlt sie den Deutschen, vom sozialen Umgang, vor allem der ,finesse‘ der Franzosen in der Konversation, zu lernen:

Les Allemands feraient bien de profiter, sous des rapports essentiels, de quelques-uns des avantages de l'esprit social en France: ils devraient apprendre des Français à se montrer moins irritables dans les petites circonstances, afin de réserver toute leur force pour les grandes; ils devraient apprendre des Français à ne pas confondre l'opiniâtreté avec l'énergie, la rudesse avec la fermeté $[. . .]^{86}$

Auf der anderen Seite sieht sie im Anschluss an Rousseau klar die degenerierten Erscheinungsformen der durch den aristokratischen ,bel esprit‘ überzogenen eigenen Zivilisation und hält diesem Defekt der Nation den Vorteil einer in Deutschland noch ,natürlichen Phantasie‘ entgegen:

Enfin, l'impatience du caractère français, si piquante en conversation, ôterait aux Allemands le charme principal de leur imagination naturelle, cette rêverie calme, cette vue profonde, qui s'aide du temps et de la persévérance pour tout découvrir. ${ }^{87}$

Mme de Staëls Beschäftigung mit Deutschland resultiert aus einer letztendlichen Faszination für die noch ungebrochene Energie der Nachbarn rechts des Rheins. Ist die französische Zivilisation von der Eigenliebe bestimmt (,amour propre'), die stets zur spöttischen Selbsterhebung über andere führt und letzten Endes jede Form eines ursprünglichen Enthusiasmus beseitigt, so hat man sich in Deutschland diesen Enthusiasmus erhalten. Er ist es, der der deutschen Philosophie des Idealismus jene Tiefe des Denkens verleiht, die man in Frankreich bei aller Finesse der Konversation vermisst. Der Enthusiasmus ist für Mme de Staël die entscheidende Antriebskraft einer Gesellschaft („le Dieu en nous“88). Und dieser Enthusiasmus ist die „qualité vraiment distinctive de la nation allemande“89.

Die Energie des durch zivilisatorische Entwicklungen noch nicht verdorbenen Deutschlands wird im Laufe des Jahrhunderts in Frankreich dann jedoch zunehmend anders wahrgenommen. Die Grausamkeiten der Französischen Revolution führen beim deutschen Bürgertum zu einer grundlegenden Frontstellung gegen den Nachbarn. Und Napoleons Kriege im Namen der Aufklärung und die

86 S. 63.

87 S. 61.

88 S. 574.

89 S. 577 f. 
Verbreitung universalistischer Werte, die die Annektierung der linksrheinischen Gebiete mit sich bringen, werden in Deutschland eher als Besatzung denn als Befreiung empfunden. Aufgrund der fehlenden Vorstellung einer realisierbaren Staatsnation bildet sich in Deutschland quasi kompensatorisch das Konzept einer ,Kulturnation‘ heraus. Dieses Konzept wird gegen Frankreich gewendet, und man besinnt sich in Deutschland auf den kriegerischen germanischen Ahnherrn Hermann den Cherusker, der die Deutschen vor den expansionistischen Bestrebungen der Römer bewahrt hatte, als deren Nachfolger sich Frankreich sieht. Hermann, den auch Mme de Staël als Gründungsfigur Deutschlands erwähnt, errichtet man in der zweiten Hälfte des 19. Jahrhunderts im Teutoburger Wald ein monumentales, nach Frankreich ausgerichtetes Nationaldenkmal. In die romantische Mythisierung der Natur, insbesondere der Rheinlandschaft, mischen sich auf deutscher Seite mit dem Beginn der Rheinkrise im Jahr 1840 aggressive politische Töne gegen Frankreichs Ansprüche auf die linksrheinischen Gebiete und die Rheingrenze. Im berühmten Lied Die Wacht am Rhein (1840) von Max Schneckenberger gewinnt die Frontstellung gegen Frankreich durch die Berufung auf den Ahnherrn Hermann zugleich Dimensionen der Kritik an der römisch-französischen Zivilisation: „Auf blickt er [der deutsche Jüngling], wo der Himmel blaut / Wo Vater Herrmann niederschaut, / Und schwört mit stolzer Kampfeslust: /,Du Rhein bleibst deutsch, wie meine Brust!“" "90 Damit bestätigen die politischen Liedermacher Schneckenberger und im gleichen Jahr auch Nikolaus Becker in seinem Lied Sie sollen ihn nicht haben, den freien deutschen Rhein (1840), aber auch die romantischen Dichter wie Joseph von Eichendorff in seinem LoreleyGedicht Waldesgespräch (1815) die auf französischer Seite bereits bei La Porte vorherrschende - im Grunde seit Tacitus überlieferte - Vorstellung von den naturverbundenen, kriegerischen und wenig an der universalistischen Zivilisation ausgerichteten Deutschen. Anlässlich seiner 1838 unternommenen Rheinreise äußert Alexandre Dumas seine Skepsis angesichts der mythischen Verklärung des Naturraums ,Rhein“ in Deutschland: „Il est difficile, à nous autres Français, de comprendre quelle vénération profonde les Allemands ont pour le Rhin. “91 Auf französischer Seite versichert man sich angesichts dieser ,profondeur mythique، der Natur erneut der zivilisatorischen Überlegenheit. In seiner boshaften Antwort auf Beckers antifranzösisches Kampflied verhöhnt Alfred de Musset in Le Rhin allemand (1841) die deutsche Verehrung der Rheinlandschaft. Er empfiehlt den

90 In: Wolf Dietrich Gumz/Frank. J. Hennecke (Hrsg.) Rheinreise. Gedichte und Lieder, Stuttgart, Reclam, 1986, S. 233 f., Str. 3, V. 13-16.

91 Excursions sur les bords du Rhin. Impressions de voyage (1841), Montréal, Le Joyeux Roger, 2008, S. 213. 
Deutschen, sich mehr auf ihre Kultur in Gestalt der Kathedralen zu konzentrieren und weniger weintrunken kriegerische Töne anzuschlagen: „Qu'il coule en paix, votre Rhin allemand; / Que vos cathédrales gothiques / S'y reflètent modestement; / Mais craignez que vos airs bachiques / Ne réveillent les morts de leur repos sanglant. “92 Nur der stets politisch engagierte, oftmals weitsichtige Victor Hugo sieht in Deutschland und Frankreich bereits zu Beginn des 19. Jahrhunderts die Achse eines gemeinsam zu gestaltenden Europa, obgleich auch er der Ansicht ist, dass die linksrheinischen Gebiete Frankreich zustehen (,[... ] rendre à la France ce que Dieu lui a donné, la rive gauche du Rhin“93). Die Einheit der beiden Völker links und rechts des Rheins bildet für Hugo die grundlegende Konstitution Europas, wobei Frankreich für die Freiheit des Gedankens, somit für die Zivilisation, und Deutschland für die Freiheit des Träumens, somit für das Gefühl und die Natur steht: „Les allemands ont la liberté de la rêverie, nous avons la liberté de la pensée. [...] L'alliance de la France et de l'Allemagne, c'est la constitution de l'Europe.“94

Es ist nicht die Rheinkrise, die das verklärende Bild Mme de Staëls und die Begeisterung für die deutsche Romantik sowie die Philosophie des deutschen Idealismus in Frankreich grundsätzlich in Frage gestellt hat. Es sind - wie Claude Digeon gezeigt hat ${ }^{95}$ - die Schlacht bei Königgrätz von 1866 und der kurz darauf folgende deutsch-französische Krieg 1870-1871, die die Franzosen haben erkennen lassen, dass die ,Naturgewalt Deutschland“ in Gestalt der erstarkten militärischen Macht Preußens eine große Bedrohung darstellt. Mit dem Sieg über Österreich im böhmischen Sadowa/Königgrätz zeichnet sich nach einer langen historischen Verspätung die Errichtung eines deutschen Nationalstaats unter preußischer Führung ab. Im Kontext des deutsch-französischen Kriegs kommt dann in Frankreich die These von den zwei Deutschland auf: Auf der einen Seite erkennt man die kulturellen Leistungen des deutschen Idealismus an, auf der anderen Seite wird das militaristische, utilitaristische und strategisch ausgerichtete Deutschland unter der Führung Bismarcks angeprangert. Zwar hatte schon 1831 der Deutschlandkenner Edgar Quinet vor dem bedrohlichen Szenario einer sich abzeichnenden deutschen Einheit gewarnt: „[...] l'unité germanique se

92 Le Rhin allemand. Réponse à la Chanson de Becker, in: Hans Neunkirchen, Le Rhin allemand dans la littérature française (Westermann-Texte), Braunschweig/Berlin/Hamburg, Westermann, 1930, S. 182 f., Str. 6, V. 26-30.

93 Rhin. Lettres à un ami (1842) (= Euvres complètes de Victor Hugo. En voyage Bd. 1), Paris, Hachette, 2018, S. S. 479; online: frantext.

94 S. 476 und S. 478.

95 Claude Digeon, La Crise allemande de la pensée francaise (1870-1914), Paris, PUF, 1959, S. $24-42$. 
prépare d'une façon [...] menaçante [...]“96 Aber erst auf der monumentalen Pariser Weltausstellung im Jahr 1867 wird diese Seite Deutschlands den Franzosen höchst präsent. In der Nachfolge der Encyclopédie raisonnée hatte die Ausstellung versucht, möglichst alle Bereiche menschlicher Arbeit, des sozialen Zusammenlebens, der Künste und der Wissenschaften in seinem ovalen Ausstellungsraum zusammenzuführen, welcher wie ein Globus eine Zivilisationsschau der gesamten Welt darstellen sollte. Was die deutsche Seite von dieser Zivilisationsschau im Zeichen von ,grandeur' und ,universalité‘ hielt, verdeutlicht sich an ihrem exponiertesten Ausstellungsstück: In der, grande galérie des machines‘ wird die, Dicke Berta‘, die größte Kanone der Zeit, ausgestellt, die nur vier Jahre später auf Paris gerichtet sein wird. Hugo sieht die Gefahr, die von dieser Geste ausgeht, spielt sie aber mit einer totalen Fehleinschätzung, nicht ahnend, dass es nur wenige Jahre später zum Krieg kommen wird, auf ironische Weise herunter:

Les énormes boulets d'acier, du prix de mille francs chaque, que lancent les canons titans fabriqués en Prusse par le gigantesque marteau de Krupp, lequel pèse cent mille livres et coûte trois millions, sont juste aussi efficaces contre le progrès que les bulles de savon soufflées au bout d'un chalumeau de paille par la bouche d'un petit enfant. ${ }^{97}$

Die ,Zwei-Deutschland-Theorie“ wird dann durch den Philosophen Elme-Marie Caro in einem Artikel 1870 formuliert: „On pourrait [...] dire qu'il y a deux Allemagnes: l'une idéaliste et rêveuse, l'autre pratique à l'excès sur la scène du monde, utilitaire à outrance, âpre à la curée."98 Der Romanist Wolfgang Leiner hat seinerzeit gezeigt, dass man in Frankreich erst nach der erneuten Bedrohung durch Deutschland im Ersten Weltkrieg bemerkt hat, dass die ,Zwei-DeutschlandTheorie“ hauptsächlich der Selbsttäuschung der Franzosen über den Nachbarn in der Zeit nach dem deutsch-französischen Krieg gedient hat. Man hatte sich eine liebgewonnene Vorstellung vom humanistischen Idealismus der Deutschen erhalten, die sich aber angesichts der weitgehenden Identifikation der deutschen Intellektuellen mit der kriegerischen Aggression 1914 als nicht länger realitätsgerecht erwies ${ }^{99}$. Stimmen, die in Deutschland der ,Zwei-Deutschland-Theorie‘ entgegengetreten waren und behaupteten, dass die Deutschen zu keiner Zeit Militarismus und Idealismus als Gegensatz begriffen hätten (,kein Widerspruch [...]

96 In einem Brief an Michelet von 1831 (in: Extrait d'Allemagne et d'Italie, repris par Edgar Quinet dans le Livre de l'exilé, Paris, Dentu, 1875, S. 202-204).

97 Victor Hugo, „Introduction”, S. XLI.

98 „Les Deux Allemagnes, Mme de Staël et Henri Heine“, in: E.-M. C., Les Jours d'épreuves 1870/71, Paris 1872, S. 53.

99 Wolfgang Leiner, Das Deutschlandbild in der französischen Literatur, Darmstadt, Wissenschaftliche Buchgesellschaft, 1989, S. 175 f. 
zwischen deutscher Wirklichkeit und deutschem Geist“100), werden nach 1945 in Frankreich reflektiert, wenn René Laurent in seinem Artikel „Y-a-t-il deux Allemagnes?" feststellt, dass schon Goethes Dichtung und Wahrheit die Begeisterung seiner Landsleute für die militärischen Erfolge des Preußenkönigs Friedrich II. erkennen lässt ${ }^{101}$. Leiner hat aber auch gezeigt, dass die Theorie von den zwei Deutschland trotz dieser ernüchternden Erkenntnisse weiterhin bis zum Ende des Zweiten Weltkriegs und darüber hinaus im französischen Bewusstsein verankert bleibt, „vielleicht auch, um nicht gezwungen zu sein, vor allem nach dem 2. Weltkrieg ein vernichtendes Urteil zu fällen“"102. Dass die Theorie sogar noch anlässlich der gemeinsamen Ausstellung deutscher Kunst von Caspar David Friedrich bis Max Beckmann im Grand Palais 2013 in Paris bis in die Gegenwart im französischen Bewusstsein virulent bleibt, wurde eingangs dieses Kapitels beschrieben. Neuere Untersuchungen haben zudem gezeigt, dass die Auffassung vom janusköpfigen Deutschland in der Nachkriegszeit in der französischen Literatur auf den Dualismus zwischen der DDR und der BRD umgepolt wird ${ }^{103}$.

100 Leiner zitiert einen Artikel aus der Neuen Rundschau von 1914 (S. 176).

101 S. 178.

102 S. 176.

103 Katja Erler, Deutschlandbilder in der französischen Literatur nach dem Fall der Mauer (Studienreihe Romania. 20), Bamberg, Erich Schmidt, 2004, S. 83 und S. 87. 